\title{
A Qualitative Examination of Continuing Bonds through Spiritual Experiences in Individuals Bereaved by Suicide
}

\author{
Danielle R. Jahn ${ }^{1, *(\mathbb{D})}$ and Sally Spencer-Thomas ${ }^{2}$ \\ 1 Psychology, SIMEDHealth, LLC., 4343 West Newberry Road, Suite 2, Gainesville, FL 32607, USA \\ 2 United Suicide Survivors International, 10122 Buena Vista Drive, Conifer, CO 80433, USA; \\ sallyspencerthomas@gmail.com \\ * Correspondence: drdaniellejahn@gmail.com; Tel.: +1-352-332-9441
}

Received: 11 July 2018; Accepted: 16 August 2018; Published: 20 August 2018

\begin{abstract}
Introduction: Suicide is a public health problem worldwide, and spiritual experiences may be important positive experiences or coping mechanisms for difficulties associated with surviving a suicide loss. Studies have found that continuing bonds through spiritual experiences are common among individuals bereaved by suicide. However, the literature lacks depth in understanding these experiences, such as sense of presence. Aims: The aim of this study was to qualitatively examine descriptions of continuing bonds through spiritual experiences after death by suicide. Method: A total of 1301 individuals bereaved by suicide provided 2443 free responses about their spiritual experiences based on four different prompts, which were analyzed using an inductive approach. Results: Nine common themes were identified, selected for interest, and reported: (1) a helpful sense of comfort; (2) a helpful sense of connection with the deceased; (3) intense sadness evoked by the spiritual experiences; (4) confusion regarding the spiritual experiences; (5) negative reminders of the deceased or negative meanings of spiritual experiences; (6) evidence of an afterlife; (7) general importance of the spiritual experiences' meaning; (8) impact of and on religious beliefs; and (9) others' responses to disclosure of suicide or spiritual experiences. Conclusion: For the overwhelming majority of participants, spiritual experiences such as a sense of presence have deep meaning and are often regarded as a positive source of healing and transformation after a suicide death.
\end{abstract}

Keywords: bereavement; postvention; spirituality; qualitative; continuing bonds; sense of presence; meaning-making; suicide

a candle shineth in the dark

lighting the way

between two hearts

one here and

one over there Jan H. for Melissa

(Gee 2009)

\section{Introduction}

\subsection{The Suicide Grief Process}

Suicide is a public health problem worldwide, with over 44,000 deaths by suicide per year in the United States alone (Centers for Disease Control and Prevention 2017) and nearly 800,000 deaths by suicide 
annually worldwide (World Health Organization 2017). The World Health Organization (2017) notes that each death by suicide affects many people, including families, communities, and whole countries. In fact, Drapeau and McIntosh (2017) estimated that 5.1 million individuals identify as survivors of suicide loss in the United States, based on the number of suicide deaths in the country from 1991 to 2015. Early estimates posited that there are at least six survivors of suicide loss for every death by suicide (Shneidman 1973), though recent research suggests that each death by suicide exposes approximately 147 people to suicide (Cerel 2015).

This body of research on suicide bereavement indicates that many individuals are bereaved by suicide, and studies suggest that these individuals may have worse outcomes than individuals bereaved by other forms of death (Currier et al. 2015b). In two separate reviews, Young et al. (2012) and Currier et al. (2015b) found that individuals bereaved by suicide were more likely to exhibit symptoms of posttraumatic stress disorder and experience complicated grief (i.e., prolonged grief that causes significant distress and interferes with functioning). Complicated grief symptoms, including preoccupying yearning for deceased, mood fluctuations and dysregulation, disconnection to others, diminished sense of self, and bleak outlook for the future, are more common among those bereaved by violent loss (Currier et al. 2015b). Reed (1998) found that individuals bereaved by suicide also reported more rejection and separation-related anxiety than did individuals bereaved by accidental deaths.

Given the large number of individuals bereaved by suicide and the potential for significant negative outcomes for these individuals, it is important to understand their bereavement experiences to potentially provide better support and resources for them, with the ultimate goal of improving outcomes among survivors of suicide loss. While emotional support through professional grief counseling and peer grief support groups have been examined among the suicide bereaved (Andriessen et al. 2017; Jordan and McIntosh 2010), little research has examined spiritual coping and the grief process among those bereaved by suicide.

\subsection{Spiritual Issues Are Connected to Suicide Loss}

Spirituality and religious practices remain important elements of cultural worldviews in many societies and are often central in human conceptualization of life and death; it is not surprising then that these issues often feature prominently in the aftermath of suicide (Castelli Dransart 2018). Because of its violent and often sudden nature, suicide deaths may be traumatic and can challenge core beliefs about benevolence, meaning, and one's own self-worth (Janoff-Bulman 2002). Individuals bereaved by suicide may experience spiritual struggle when core beliefs and tenets of faith are tested (Wortmann et al. 2011).

Spirituality and religion are often looked to for answers and support when individuals face life challenges such as suicide that are not in line with their beliefs (Currier et al. 2015b). When violence is human-initiated (Currier et al. 2015b) and a redemptive narrative is not readily apparent, survivors of suicide loss sometimes find their global meaning systems called into question (Castelli Dransart 2018; Wortmann et al. 2011). Many religions hold stigmatized views of suicide that can lead those bereaved to experience suicide as a punishment from a deity for the bereaved or their deceased loved ones (Castelli Dransart 2018). However, coping post-trauma often involves rebuilding assumptions about the world (Janoff-Bulman 2002), a process in which faith traditions and spiritual practices can play a key role (ter Kuile and Ehring 2014). What often results is a push-pull paradox of traumatic grieving (Spencer-Thomas 2013) where the bereaved feel a disrupted attachment to the deceased (Currier et al. 2015a).

According to Zinnbaur et al. (1999) engagement in religious institutions and confidence in religious leaders are in decline; however, individuals are not less religious or spiritual. In fact, a pattern of increasing personalized expressions of religious pluralism have been found (Beckford 2014; Zinnbaur et al. 1999). In one large study of individuals bereaved by suicide (Jahn and Spencer-Thomas 2014), nearly half of survivors of suicide loss (43\%) reported that their religious affiliation was very important to them; a similar percentage (46\%) indicated that their loss did not change their religiosity or spirituality; and $36 \%$ 
of participants indicated that they became more religious or spiritual after their loss (Krysinska et al. 2017). Participants also reported high levels of intrinsic religiosity, as over half participants indicated that they experienced the presence of the divine in their lives, that they carried over their religion into all aspects of their lives, and that their religious beliefs laid behind their approach to life (Krysinska et al. 2017).

Spirituality and religiosity can take many forms, particularly in the context of bereavement. Spirituality may include a transcendent dimension (i.e., "a way of being and experiencing that comes about through awareness of a transcendent dimension ... ", Elkins et al. 1988, p. 10; "a transcendent dimension within human experience ... discovered in moments in which the individual questions the meaning of personal existence and attempts to place the self within a broader ontological context", Shafranske and Gorsuch 1984, p. 231). Similarly, spirituality may be experienced as extraordinary events or experiences (i.e., "a state of being related to a divine supernatural, or transcendent order of reality, or alternatively, as a sense of awareness of a super reality that goes beyond life as ordinarily experienced", Wuthnow 2001, p. 307). Within this framework, continuing bonds, meaning-making, and sense of presence experiences may be connected to grief after suicide loss. Thus, understanding spiritual experiences related to suicide loss may improve understanding of this complex form of grief.

\subsection{Spiritual Experiences: Continuing Bonds, Sense of Presence, and Meaning-Making}

\subsubsection{Continuing Bonds}

Early formulations of "successful" grief coping promoted emotional disengagement (e.g., through ending bonds with the deceased) as a goal for healing; however, recent research has rejected emotional disengagement as the goal of bereavement (Steffen and Coyle 2010). The shifting of the grief paradigm from emotional disengagement to our current understanding of continuing bonds is largely credited to Klass et al. (1996). Klass et al. (1996) posited that healthy grief is not about detachment, acceptance, and moving on in a linear way, but rather creating a new relationship with the deceased, linking the grief process to a larger understanding of natural human attachment theory, and appreciating cross-cultural practices of grief and mourning.

Out of this new paradigm emerged an appreciation of continuing bonds between the deceased and the bereaved. Some have described the continuing bonds experience as existing on two levels (Currier et al. 2015a; Gee 2009). The first level is an internal representation related to memories, such as evoking a feeling of connection with the deceased by reminiscing or reflection (Harper et al. 2011). Sometimes this level of continuing bonds can be expressed by continuing a legacy started by the deceased or by pursuing life goals in the deceased's honor. The second level of continuing bonds is described as an interactive connection, whereby the bereaved experiences a sense of presence of the deceased, and may ask the deceased for guidance or seek comfort. Here, the deceased is experienced as a separate entity and connections may be experienced as "deceased-initiated" (Root and Exline 2014).

Continuing bonds focus on the relationship with the deceased continuing on in a different form, such as a mental attachment, rather than a physical relationship (Wood et al. 2012). Behavioral scientists have been paying increasing attention to how these experiences affect the grief process (Currier et al. 2015a). When continuing bonds are positive, they may provide a "secure base" for facilitating post-loss emotional processing, worldview reframing, and possible growth (Currier et al. 2015a). Continuing bonds, particularly those that occur through spiritual experiences, are common among bereaved individuals (Drewry 2003; Kwilecki 2009), and may be beneficial in the grieving process (Drewry 2003). Notably, spirituality and continued spiritual connections play an important role in grief and coping for many bereaved individuals (e.g., Chapple et al. 2011; Sormanti and August 1997; Wortmann and Park 2008). The role of continued spiritual connections in grief and coping may be especially important for individuals bereaved by suicide, based on previous research (Begley and Quayle 2007; Wood et al. 2012).

In a large sample of survivors of suicide loss, $63 \%$ reported having spiritual experiences that represented continuing bonds with the deceased (Jahn and Spencer-Thomas 2014). Additionally, 
of those who had spiritual experiences, nearly $75 \%$ reported that the experiences had been helpful in their grieving process, whereas less than $5 \%$ reported that the experiences had been harmful (Jahn and Spencer-Thomas 2014); respondents most often reported emotions such as love and peace associated with these experiences, though sadness was also a common feeling (Jahn and Spencer-Thomas 2014).

\subsubsection{Sense of Presence}

Steffen and Coyle (2012) summarized the description of "sense of presence" experiences as "sensory impressions" that can involve visual, auditory, tactile, and olfactory qualities of the deceased or "quasi-sensory" feelings of non-specific awareness of the deceased. The experiences have often been characterized as "vivid," "extraordinary," "paranormal," and "anomalous" (Parker 2005). Other researchers have included other phenomena such as vivid dreams and uncanny coincidences (Wright 2006) or experiences with mediums (Lester 1982) as also having a similar effect of an experience of an after-death connection. Rees (1971), Steffen and Coyle (2010), and Wiener et al. (1996) found that between $50 \%$ and $80 \%$ of bereaved individuals experience some sense of presence of a deceased person who had been close to them while alive.

In the previous theories of grief, experiences such as sensing the presence of the deceased were considered hallucinations, denial mechanisms, or dysfunctional searching (Steffen and Coyle 2010). Hayes and Leudar (2016) argued that sense of presence experiences are not hallucinations because they are not symptoms of an underlying mental health condition, but rather they are rooted in actual experiences of the past relationship history and are not often problematic.

Keen et al. (2013) discovered multiple themes among people who experienced "a sense of presence," including the experiences being unique and personally distinctive to the deceased and the bereaved's prior beliefs, as well as understandings being congruent with the experienced sense of presence. Additional Keen et al. (2013) found that the bereaved's emotional impact shifted from initial fear to comfort after repeated experiences. In this study, the bereaved also expressed how important it was to have the experiences validated by learning that others have had similar experiences (Keen et al. 2013). Research exploring the benefits of these experiences has shown that individuals who report them have less loneliness, feel less intense pain from the loss, and believe that they have received guidance or encouragement from the deceased (Hayes and Leudar 2016). Nevertheless, sense of presence experiences are not always healing and may be associated with increased depression or more severe grief in the short-term (Hayes and Leudar 2016). In the cases where they cause distress, there had often been relationship challenges with the deceased during life (Hayes and Leudar 2016).

\subsubsection{Meaning-Making}

Sense of presence experiences may be related to meaning-making in bereaved individuals. Because suicide can challenge core beliefs and religious tenets, sense of presence experiences can help individuals integrate their experiences into a new worldview (Steffen and Coyle 2012). Steffen and Coyle (2010) suggested that: "The experience of sensing the presence of the deceased ... could be regarded as constituting a spiritual experience that can facilitate increased coping, meaning-making, and growth ..." (p. 3). In particular, sense of presence experiences can help with the sense-making, benefit-finding, and identity change processes that can lead to post-traumatic growth (Steffen 2014; Steffen and Coyle 2010). In fact, these experiences are no longer considered a sign of pathology (Hayes and Leudar 2016), but a framework for meaning-making after experiencing the death of a loved one (Parker 2005).

Parker (2005) noted that a significant loss can send someone into a spiritual crisis (e.g., loss of purpose, experience of non-being, and relentless search for meaning). Parker (2005) found that, for many, these experiences of sense of presence helped facilitate adaptive spiritual outcomes of feeling grounded and finding spiritual growth. That is, spiritual experiences can help bereaved individuals find meaning. In qualitative interviews with bereaved individuals, Steffen and Coyle (2011) found 
three central themes related to spiritual experiences, including finding benefit in continuing bonds and, importantly, meaning-making in the spiritual and religious sense.

\subsection{Aims}

Despite the importance and common occurrence of spiritual experiences such as continuing bonds through sense of presence, the literature lacks depth in understanding the spiritual experiences of individuals bereaved by suicide. Quantitative, descriptive statistical approaches are important to understanding the frequency and correlates of these experiences, but this type of approach may miss important concepts and meaning-making. Therefore, the aim of this study was to qualitatively examine descriptions of the spiritual experiences (e.g., continuing bonds through sense of presence) of individuals bereaved by suicide, utilizing an inductive approach to code data without any predefined expectations or categories.

The purpose of this study was to further understanding of how individuals bereaved by suicide experience and make meaning of their spiritual experiences. The study is unique as it explores concepts of continuing bonds and sense of presence within a specific bereaved population, those bereaved by suicide. Furthermore, the study is unique because it involves a qualitative analysis of a very large sample through open-ended survey questions. This research strategy is critical because people who have experienced spiritual sense of presence phenomena may not disclose to others for fear of being judged or stigmatized (Castelli Dransart 2018). This anonymous and confidential methodology helped bypass this barrier to data collection.

\section{Methods}

\subsection{Sampling}

Detailed information about participants and procedure can be found in Jahn and Spencer-Thomas (2014) and Krysinska et al. (2017). Briefly, participants were 1301 individuals bereaved by suicide, who were recruited online (e.g., emails to professional listservs and suicide bereavement networks, and posts to social media) through chain-referral sampling. Data were collected anonymously through online software, and the Texas Tech University Institutional Review Board approved all procedures. Participants did not provide informed consent before participation, as the study was deemed exempt, and were instead provided with a description of the study and the voluntary nature of participation.

Participants were mostly female $(n=1155 ; 88.8 \%)$, middle-aged (ages $40-64 ; n=744 ; 57.2 \%)$, and living in the United States $(n=1199 ; 99.2 \%)$. Participants most often reported being bereaved by the loss of a child to suicide ( $n=362 ; 27.8 \%)$, followed by a sibling $(n=235 ; 18.1 \%)$, spouse/partner ( $n=204 ; 15.7 \%)$, or parent/stepparent $(n=180 ; 13.8 \%)$. Participants mostly reported relatively recent losses, with most occurring $1-3$ years ago $(28.9 \% ; n=376),<1$ year ago $(25.7 \% ; n=334)$, or $4-10$ years ago $(22.0 \% ; n=286)$. Over half of the sample reported continuing bonds through spiritual experiences related to the individual who had died by suicide $(63.0 \% ; n=819)$. Over half of participants $(57.9 \%$; $n=746)$ identified as being affiliated with an organized religion; a majority of these $(37.4 \% ; n=482)$ were Protestant Christian. Additionally, 27.2\% $(n=350)$ identified as spiritual but not associated with an organized religion.

\subsection{Instruments}

Two questionnaires were used for the larger study from which the data were drawn. The first questionnaire assessed demographic and history information to characterize the sample. The second questionnaire, the Spiritual Experiences of Survivors of Suicide Questionnaire (Jahn and Spencer-Thomas 2014), is a face-valid assessment of the spiritual experiences of individuals bereaved by suicide. This questionnaire contained both quantitative and qualitative questions (for quantitative analyses, see Jahn and Spencer-Thomas 2014; Krysinska et al. 2017). As part of this questionnaire, four open-ended questions were asked. The first asked participants to elaborate on a previous multiple 
choice response regarding whether they found spiritual experiences to be harmful, helpful, or neither harmful nor helpful.

The second prompted respondents to explain the meaning of any spiritual experiences that occurred (i.e., "What did the spiritual experiences mean to you?"), and was immediately followed by a third open-ended question asking how religious or spiritual backgrounds may have influenced the respondents' experiences (i.e., "How do you think your current or previous religious background influenced the spiritual experiences?"). Finally, the last question in the survey stated, "If you would like to share any other details about your experience, please do so here," to allow participants to share any other thoughts or comments that may not have been captured by the previous survey questions. All responses were optional.

\subsection{Analyses}

An inductive thematic approach was used to analyze the data (Braun and Clarke 2006). In this method, researchers use judgment to determine themes based on frequency of mention and importance to the overall research question. The assumptions that informed the analysis were based upon the previous research on the impact of continuing bonds on the grief process and the grief complications often facing people bereaved by suicide mentioned above. The research team followed the phases suggested by Braun and Clarke (2006) to identify, analyze, and report patterns within the data as follows.

All responses were copied into a spreadsheet, with each column representing one question and each row representing one participant. Codes were then assigned to corresponding cells. First, the first author and a graduate student who assisted with analyses reviewed all of the responses to familiarize themselves with the data. Then, each separately coded all of the responses for the second question regarding the meaning of the spiritual experiences, using the inductive thematic approach. Each response could be assigned multiple codes, if multiple themes were addressed in the response. For the second question, 706 responses were coded. Those that were not coded $(n=10)$ included responses such as, "see above" or "n[/]a." A total of 1154 codes were initially assigned to the 706 responses. Of these 1154 codes, 996 matched, for an inter-rater reliability rate of $86.3 \%$. The differing codes were resolved through discussion. Given the high reliability rate between coders for this question, one coder (the first author) then used the same inductive approach to code the responses to the remaining questions. In total, $29.3 \%$ of all responses were coded separately by two researchers and the remaining were coded by only the first author. The coded data were then organized into themes by the first author; the themes were reviewed, curated, and named by the second author.

\section{Results}

\subsection{Overview}

In total, 2443 free responses were provided. A total of 584 responses were provided to the first open-ended question regarding how the spiritual experiences were perceived, 716 responses were given regarding what the spiritual experiences meant, 696 participants answered the question about how their religious backgrounds influenced their experiences, and 447 comments were made in response to the last prompt regarding other comments.

For the first question, which asked participants to elaborate on the harmfulness or helpfulness of their spiritual experiences, there were a total of 584 responses, 49 of which were deemed not relevant. The 49 uncoded responses included details about the content of the spiritual experiences (versus information about helpfulness or harmfulness, or meaning-making), information about religion broadly (e.g., "I don't believe that God causes evil to happen, but that evil exists because of the fallen nature of this world. Evil happens because man has free will, and God has given man free will because we are given the choice to love Him."), descriptions of others' spiritual experiences (e.g., "I do not feel that they helped my 4 [year] old to understand the permanence of his father's death"), 
or other information about the participant's functioning (e.g., "A couple of profound coincidences led me to volunteering with [the American Foundation for Suicide Prevention] and community walks where I've met many people whom I can relate with.", "I ended up writing a report on suicide."). From the 535 responses that were deemed relevant, 872 codes were noted. In terms of the second question, which asked participants to describe what the spiritual experiences meant to them, there were 716 responses to this question. After codes were reconciled between two coders (see Methods for details), a total of 17 responses were deemed irrelevant and 1101 codes were assigned to the relevant responses.

In total, 696 responses were provided to the third question regarding how the participant's current or previous religious background influenced the spiritual experiences, and 127 were deemed irrelevant. This is a high number of irrelevant responses, and is the result of many responses explaining the participant's background or religious beliefs without the context of their spiritual experiences (e.g., "My faith is very strong and sustains me.", "I don't practice religion, I believe in God ... "). On those responses deemed relevant, 575 codes were assigned.

Responses to the last open-ended question (i.e., "If you would like to share any other details about your experience, please do so here.") varied widely; 447 responses were recorded in total, with 15 responses not coded. The responses that were not coded included statements offering to talk more about experiences if it would be helpful or indications that the participant did not have any additional comments. Most of these provided more details about the content of the spiritual experiences or reiterated the meaning assigned to them, sometimes noting that the individual bereaved by suicide would welcome more spiritual experiences if they were to occur $(n=101)$. These codes have been incorporated into the thematic analysis.

\subsection{Spiritual Experiences as Helpful or Harmful}

In Jahn and Spencer-Thomas (2014), 74.5\% of respondents found the experiences to be helpful, $19.9 \%$ found them to be neither helpful nor harmful (mixed experiences), and $4.8 \%$ found them to be harmful. Elaborating on this question, participants most often reported their spiritual experiences as helpful in a number of ways, including predominantly finding comfort in the spiritual experiences that they had.

\subsubsection{Theme \#1: (Helpful) Finding Comfort}

Predominantly, codes indicated that the spiritual experiences were helpful because they provided comfort, acceptance, or happiness to the individual bereaved by suicide $(n=309)$ and communicated that the deceased was safe, at peace, or in an afterlife $(n=259)$; Participants discussed feelings of love and hope that were associated with spiritual experiences. For example:

"My brother told me he was ok[ay], happy, free from torments of life and in heaven. It made me so happy."

"I felt my son was at peace, therefore I found both peace and acceptance[.]"

"These experiences facilitated a grace and peace that transcended the pain of loss[.]"

"At first I was worried that he was sending me a bad message, then I realized he is just with me and still by my side. It [g]ave me comfort and happiness."

\subsubsection{Theme \#2: (Helpful) Connection and Communication}

Responses also commonly indicated a theme that the deceased was present with the bereaved individual or continued to live on $(n=238)$. Spiritual experiences represented a continued connection, communication, or closeness with the deceased $(n=85$; e.g., "It meant that there was still a connection between us.", "It was a message "Thank you for loving me.'”, "[T] hat the relationship was not over it just changed to a new kind of experience[.]"). 
Less often, participants interpreted the experiences as conveying some other message from the deceased ( $n=86$; e.g., "My son exp[1]ained some questions I had.", "Let me know everything would be [okay] ... I would get the job ... and I did."); providing assurance that the deceased protects or watches over the bereaved $(n=59)$; and suggesting that the bereaved individual will see the deceased again $(n=26)$.

\subsubsection{Theme \#3: (Mixed Experiences) Evoking Sadness or Anger}

Through this qualitative analysis, we explored the $20 \%$ of respondents who indicated that their spiritual experiences were neither helpful nor harmful (Jahn and Spencer-Thomas 2014), as well as the small percentage who identified the experiences as harmful. Many of the mixed experiences were due to overwhelming sadness evoked by the spiritual experiences.

Responses indicated that negative emotions were present in association with the spiritual experiences $(n=99)$, but these tended to be sadness about missing the deceased or disappointment that the bereaved would not be able to see the deceased again, rather than anger at the deceased or at the spiritual experiences; quite a few participants reported mixed emotions associated with the spiritual experiences. For example:

"It was only two weeks ago that my father took his life and seeing his smiling face just hurts this soon ..."

"Help with the grieving but also sadness to think of how he must of felt up to the time it happened."

"In my dream he was telling me goodbye and telling me why he had to do it so I found some peace in that but at the same time it made me very sad because he was gone."

However, some respondents did find the intensity of sadness related to the spiritual experiences distressing, noting "I often woke crying because of them[.]" or "[I] just found a profound sense of loss, pain, sorrow[,] etc."

Negative emotions such as fear and anger were also noted in conjunction with the meaning of the spiritual experiences somewhat frequently $(n=43)$, and again sometimes included mixed emotions, such as "[W]hile it brought some comfort, it brought a lot of anger and confusion about why he did it and what we were supposed to do without him in our life[.]", "It depended on the experience. One time it scared me, so I became angry. Other times they've made me laugh.", and "Scared me to think that death did not necessarily bring peace."

\subsubsection{Theme \#4: (Mixed Experiences) Confusion}

Though not particularly common, 30 responses indicated confusion about the experiences or being uncertain of their meaning (e.g., "The 'visit' from my sister has left me confused spiritually. I also wish she would visit again."). A total of 25 participants questioned the authenticity of their spiritual experiences. Additionally, seven responses indicated that the respondents did not assign meaning to the spiritual experiences, seven suggested that the experiences occurred only because the bereaved individual missed the deceased, and six reported that the experiences were simply the bereaved trying to understand of make sense of the suicide. Some participants were not sure about the meaning of the experiences $(n=28)$ or could not explain the meaning they assigned to the experiences $(n=5)$.

\subsubsection{Theme \#5: (Harmful) Negative Reminders or Meanings}

While only $4.8 \%$ of respondents reported they found their spiritual experiences harmful (Jahn and Spencer-Thomas 2014), the qualitative responses were analyzed to help elucidate why they caused harm.

Responses indicating that the spiritual experiences were harmful were far less common than those explaining the experiences' helpfulness, but they were present. For example, 17 responses found that 
the experiences communicated that the deceased was not at peace (e.g., "I think she may be stuck in limbo and unhappy.", " . . I was very upset, thinking that he was still distressed.") and 10 responses indicated that the experiences were negative reminders of the deceased. Responses in this theme included: "The images were threatening to me[.]", "That she was angry and was punishing me in my dreams.", "That my father had not yet found peace.", and "That he intensely regretted what he had done."

\subsection{Meaning-Making Related to Spiritual Experiences}

Beyond the continuum of helpful and harmful in the grief process, participants' responses also clustered around themes of afterlife, importance, religiosity, and disclosure.

\subsubsection{Theme \#6: Evidence of an Afterlife}

Respondents sometimes discussed interpreting the spiritual experiences as evidence that an afterlife exists $(n=77)$ : "That there is life after death." and "The experiences have helped me believe even more in a further experience after death."

\subsubsection{Theme \#7: Importance of Spiritual Experiences}

One theme that arose in the context of the second question was the idea that the spiritual experiences were very important, powerful, or meaningful, without additional elaboration regarding more specific meaning (e.g., "It means the world to me.", "Everything."; $n=45$ ). Similar responses that generally conveyed that the experiences were very meaningful included:

"[T] hey have meant the world to me as they prove that my son is ok and we can still communicate."

"They were powerful and loving experiences that I treasure and would be extremely happy if I had more of them!"

"My experiences have been deeply meaningful and have helped me tremendously. I wish I could have them more often."

\subsubsection{Theme \#8 Impact of and on Religious Framework and Spirituality}

In response to the third question regarding the impact of participants' religious backgrounds or beliefs on their spiritual experiences, a large majority of responses indicated that there was no impact. In total, 216 responses indicated that religious background or beliefs did not impact spiritual experiences (e.g., "I don't think my religious background had any effect[.]", "I don't believe it did because the [C]atholic church teaches many things I don't agree with.", "My religious background plays a big role in my continued grief and questioning, but no role in spiritual experiences as described in this study.").

Less commonly, individuals bereaved by suicide indicated that their religious backgrounds made them more open to or accepting of spiritual experiences $(n=93)$ or that a previous belief in an afterlife allowed the experiences to occur $(n=58)$ : "My current beliefs allowed me to be open to receiving messages and comfort from him.", "It kept me from dismissing the experiences \& accepting them \& learning from them ... ", and "Perhaps religious instruction prepared me for experiencing these things."

Others $(n=12)$ indicated that their religious beliefs were helpful in terms of spiritual experiences, without providing additional clarification. Finally, quite a few participants indicated that they were not sure how their religious background influenced their spiritual experiences $(n=65)$, that their religious beliefs had little impact (without further explanation; $n=30$ ), or that these beliefs had a substantial impact (without additional information; $n=26$ ). Relatively few indicated that the experiences contradicted previous religious beliefs $(n=22)$ or that their religious background was not helpful in the context of the spiritual experiences $(n=6)$. 
Participants also discussed changes in their religion and religious beliefs, either as a result of the death by suicide or the related spiritual experiences. A number of participants noted anger at or blame of a deity related to the death by suicide, reduction in their religiosity or religious participation, and the notion that their faith had been shaken or damaged $(n=89)$ : "I would say I became less religious and more spiritual[.]", "I was angry that anyone would even suggest that there was a good powerful God after my partner's suicide. It seemed an insult.", "I had a strong relationship with Jesus. The only thing I asked for was to help my father and mother to be happy. My father eventually [died by] suicide and my mother[']s life worsened as a result. I discovered that religion was a waste of time.", and "I lost my faith in God and his plan[.]"

Fewer respondents noted that their religious beliefs or participation did not change $(n=11)$, or reported that their spirituality or faith was stronger $(n=66)$ and that they relied on faith or deity for coping $(n=29)$ : "God is helping me survive this terrible pain ... I'm sad, scared and angry at times and comforted at times. God is with me through it all.", "Through all of the pain, it took quite a while for my spiritual life to grow stronger. My faith has helped me grow in many areas and to realize what is REALLY important. It has also helped me make meaning of the loss and honor [his] life and memory.", "I've always been spiritual, but this deepened my beliefs more than I thought possible."

Thus, while many of the participants indicated that their religious background did not impact their spiritual experiences, a large number of people expressed that their connection to religion was impacted by the suicide death and their spirituality was often stronger or transformed by the spiritual experiences.

\subsubsection{Theme \#9 Others' Responses to Disclosure}

The final common theme was regarding others' responses to the death by suicide or to the disclosure of the spiritual experiences $(n=80)$. These were often responses from the religious community or leaders, and some were regarded positively, while others were viewed negatively:

"The majority of people I have talked with about my experience have been very supportive and accepting ... I still have fears about people judging me, my dad, and my family because of the stigma surrounding suicide and so I rarely tell others how my dad died."

"I felt let down by my church community-whose outlook seems to be that anyone who died by suicide or lost a son to suicide must be a sinner[,] have failed to pray enough[,] failed in some way to be a good parent... Not the same as the reaction to a cancer death ..."

"[T]he priest was very loving and supportive and helped us by tremendously. [I]n his eulogy he spoke of how God loved [her] and acknowledged her struggles."

"Most of my church community responded supportively. A few misunderstood how suicide grief is different than other grief and their well intentioned attempts at help simply made me feel worse."

“My pastor was so loving \& kind. He was reassuring \& supportive from the very beginning!"

\section{Discussion}

Collectively, the results from this inductive thematic qualitative approach overwhelmingly indicated that individuals bereaved by suicide often find spiritual experiences to provide comfort or connection with the deceased. Additionally, although negative emotions were noted by participants, these often related to sadness that they could no longer be with the deceased, rather than anger at the deceased or sadness about the experiences themselves (though these types of responses did occur rarely). In this study, individuals bereaved by suicide most often indicated that their religious background did not have a significant impact on their spiritual experiences, although some reported that their religious beliefs made them more open to experiencing continuing bonds through spiritual experiences, sometimes due to previous beliefs in an afterlife or deity. Few reported that the spiritual 
experiences conflicted with their previous religious beliefs or that their religious background made the experiences unhelpful or disturbing. Another common theme was the bereaved individuals' lessening of faith or anger at a deity, as well as how other people in their lives responded to the death by suicide and/or spiritual experiences.

Ultimately, nine themes were identified in relation to the experiences of individuals bereaved by suicide: (1) a helpful sense of comfort; (2) a helpful sense of connection with the deceased; (3) intense sadness evoked by the spiritual experiences; (4) confusion regarding the spiritual experiences; (5) negative reminders of the deceased or negative meanings of spiritual experiences; (6) evidence of an afterlife; (7) general importance of the spiritual experiences' meaning; (8) impact of and on religious beliefs; and (9) others' responses to disclosure of suicide or spiritual experiences. The first theme was very common, and respondents indicated that they found comfort, acceptance, or happiness in the spiritual experiences, and that these experiences communicated that the deceased was safe, at peace, or in an afterlife. The second theme, which was also common, indicated connection and communication; the deceased was present with the bereaved individual or continued to live on, and communicated messages from the deceased.

However, some negative emotions were also present, as noted in the third theme. Participants reported sadness about the experiences or missing the deceased, as well as fear and anger at times. Many of these negative emotions were in the context of mixed emotions. Confusion about the spiritual experiences were sometimes noted, creating the fourth theme. Rarely, the spiritual experiences were viewed as negative reminders of the deceased (e.g., negative traits or events during their life) or conveying things such as the deceased not being at peace.

Participants also indicated that the spiritual experiences were evidence of an afterlife. Another common theme was that the spiritual experiences had significant meaning (e.g., "the world" or "so much") without more elaboration. Responses that made up the eighth theme mostly indicated that participants' religious backgrounds allowed them to make meaning of their spiritual experiences, though sometimes these religious backgrounds did not influence their experiences. Additionally, participants reported mixed impact of their loved ones' suicides or spiritual experiences on their religious beliefs. Similarly, participants reported mixed responses from others in relation to disclosing their loved ones' suicides or their spiritual experiences.

Taken in the context of previous research, the current findings serve to deepen understanding of spiritual experiences and continuing bonds among individuals bereaved by suicide. Jahn and Spencer-Thomas (2014) found that approximately 75\% of individuals bereaved by suicide found their spiritual experiences to be helpful, consistent with the large number of participants who found comfort, peace, or happiness in the spiritual experiences and interpreted them positively. Similarly, Drewry (2003) noted that continuing bonds can help in the grieving process, and this was a common theme among responses in the current study. Given that multiple researchers (e.g., Begley and Quayle 2007; Wood et al. 2012) have found that spirituality and spiritual connections may be especially important for survivors of suicide loss, it is unsurprising that these were common responses among participants in this research.

The findings of this study suggest that spiritual experiences, such as continuing bonds through experiencing the presence of the deceased individuals, are generally beneficial to individuals bereaved by suicide. This is consistent with Klass et al.'s (1996) conceptualization of healthy grief, which is not about detachment, but about continuing bonds representing a new relationship with the deceased. These continuing bonds are common among individuals bereaved by suicide (Jahn and Spencer-Thomas 2014) and are helpful in coping in this population (Begley and Quayle 2007; Wood et al. 2012). This study elucidated ways in which continuing bonds are helpful (e.g., sense of comfort and connection).

In particular, sense of presence experiences are common (Rees 1971; Steffen and Coyle 2010; Wiener et al. 1996) and can be comforting, though they need to be validated by others (Keen et al. 2013). They can help reduce the pain of loss and represent encouragement from the deceased (Hayes and 
Leudar 2016). Participants in this study often reported such comfort and messages from the deceased when experiencing the sense of presence of the deceased. They also often reported encouragement in messages from the deceased in the sense of presence experiences.

Finally, as noted in multiple previous studies (e.g., Steffen and Coyle 2011; Steffen and Coyle 2012), meaning-making was identified in the sense of presence experiences among participants in this study. The challenging of core beliefs and religious tenets that may occur when a loved one dies by suicide can be ameliorated via the meaning-making associated with sense of presence experiences (Parker 2005; Steffen and Coyle 2012). Previous qualitative research found that identifying benefit in continuing bonds and spiritual and religious meaning-making were important parts of sense of presence experiences (Steffen and Coyle 2011).

The findings of this study emphasize the importance of discussing spirituality in the context of mental health, and may highlight the need for collaboration between mental health providers and spiritual leaders, as healing after a loss by suicide may require both mental health and spiritual or religious support.

In terms of limitations, this study's recruitment methods and sample characteristics (i.e., primarily from the United States, female, and middle-aged) may limit generalizability. This type of sampling may have also biased results; individuals bereaved by suicide with more positive spiritual experiences may have been more likely to participate in the research, as discussing negative spiritual experiences may be challenging and therefore individuals may avoid doing so. Additionally, because typed free responses were used for analysis, follow-up questions for clarity were precluded when gathering qualitative information. Though previous research has also used online question responses for qualitative analysis (e.g., Hipp et al. 2017), future research may benefit from interviewing individuals bereaved by suicide to continue exploring their views of bereavement and continuing bonds through spiritual experiences.

\section{Conclusions}

In summary, suicide bereavement can be complicated for many, and spiritual experiences such as a sense of presence of the deceased may help provide meaning-making and continuing bonds. These spiritual experiences may help in the bereavement process. By examining the qualitative responses of a very large sample of people bereaved by suicide, this research reaffirms that spiritual experiences have deep meaning and are often regarded as positive in many individuals bereaved by suicide. The large number of individuals personally affected by suicide (e.g., Berman 2011; Cerel 2015), as well as the potential for negative outcomes among these individuals (e.g., more complicated grief, elevated suicide risk; (Krysinska 2003; Young et al. 2012)) and the beneficial nature of spiritual experiences in the grieving process (e.g., Begley and Quayle 2007; Wood et al. 2012), indicate that understanding continuing bonds through spiritual experiences is an important insight to processing grief. As these experiences may allow survivors of suicide loss to make meaning after a death by suicide, discussion of such experiences may be helpful in support groups for individuals bereaved by suicide, in psychotherapy, or in faith or spiritual communities. Reducing stigma and providing space for these individuals to process and make sense of spiritual experiences may improve well-being and support the grieving process.

Author Contributions: D.R.J. and S.S.-T. conceived and designed the study; S.S.-T. recruited participants; D.R.J. conducted data collection; D.R.J. analyzed the data; D.R.J. and S.S.-T. wrote the paper; and S.S.-T. edited and reviewed the paper.

Funding: This research received no external funding.

Acknowledgments: The authors would like to thank Quintin Hunt for his assistance in analyzing the qualitative data, and Kelly Cukrowicz for her support in obtaining the necessary approval for this study.

Conflicts of Interest: The authors declare no conflict of interest. 


\section{References}

Andriessen, Karl, Krysinska Karolina, and Onja Grad. 2017. Postvention in Action: The International Handbook of Suicide Bereavement Support. Boston: Hogrefe.

Beckford, James. 2014. Re-Thinking Religious Pluralism. In Religious Pluralism: Framing Religious Diversity in the Contemporary World. Edited by Giuseppe Giordan and Enzo Pace. Cham: Springer, pp. 15-29.

Begley, Mary, and Ethel Quayle. 2007. The Lived Experience of Adults Bereaved by Suicide: A Phenomenological Study. Crisis 28: 26-34. [CrossRef] [PubMed]

Berman, Alan L. 2011. Estimating the Population of Survivors of Suicide: Seeking an Evidence Base. Suicide and Life-Threatening Behavior 41: 110-16. [CrossRef] [PubMed]

Braun, Virginia, and Victoria Clarke. 2006. Using thematic analysis in psychology. Qualitative Research in Psychology 3: 77-101. [CrossRef]

Castelli Dransart, Dolores Angela. 2018. Spiritual and religious issues in the aftermath of suicide. Religions 9: 153. [CrossRef]

Centers for Disease Control and Prevention. 2017. “Leading Causes of Death Reports, 1981-2015.” WISQARS. Available online: https:/ / webappa.cdc.gov/sasweb/ncipc/leadcause.html (accessed on 19 December 2017).

Cerel, Julie. 2015. We are all connected in suicidology: The Continuum of "Survivorship". Paper presented at the Annual Conference of the American Association of Suicidology, Atlanta, GA, USA, April 18.

Chapple, Alison, Swift Chris, and Sue Ziebland. 2011. The role of spirituality and religion for those bereaved due to a traumatic death. Mortality 16: 1-19. [CrossRef]

Currier, Joseph, Irish Jennifer, Neimeyer Robert, and Joshua Foster. 2015a. Attachment, Continuing Bonds and Complicated Grief Following Violent Loss: Testing a Moderated Model. Death Studies 39: 201-10. [CrossRef] [PubMed]

Currier, Joseph M., Kuhlman Shane, and Phillip N. Smith. 2015b. Spirituality, Meaning and Suicide. Spirituality in Clinical Practice 2: 82-83. [CrossRef]

Drapeau, Christopher W., and John L. McIntosh. 2017. “U.S.A. Suicide: 2015 Official Final Data." American Association of Suicidology. Available online: http://www.suicidology.org/Portals/14/ docs / Resources / FactSheets / 2015/2015datapgsv1-wLabelchgs.pdf?ver=2017-12-07-205245-343 (accessed on 19 December 2017).

Drewry, Damaris J. 2003. Purported After-Death Communication and Its Role in the Recovery of Bereaved Individuals: A Phenomenological Study. Paper presented at the Annual Conference of the Academy of Religion and Psychical Research. Available online: http:/ / connection.ebscohost.com/c/articles/10761343/ purported-after-death-communication-role-recovery-bereaved-individuals-phenomenological-study (accessed on 19 August 2018).

Elkins, David N., L. James Hedstrom, Lori L. Hughes, J. Andrew Leaf, and Cheryl Saunders. 1988. Toward a Humanistic-Phenomenological Spirituality. Journal of Humanistic Psychology 28: 5-18. [CrossRef]

Gee, Tony. 2009. Honouring the Spiritual Dimension for Survivors: The Development of a Hocokah or Healing Circle. Paper presented at the International Association of Suicide Prevention's World Congress, Montevideo, Uruguay, October 27-31.

Harper, Mairi, O'Connor Rory, Dickson Adele, and Ronan O'Carroll. 2011. Mothers Continuing Bonds and Ambivalence to Personal Mortality after the Death of their Child-An Interpretive Phenomenological Analysis. Psychology, Health and Medicine 16: 203-14. [CrossRef] [PubMed]

Hayes, Jacqueline, and Ivan Leudar. 2016. Experiences of Continued Presence: On the Practical Consequences of 'Hallucinations' in Bereavement. Psychology and Psychotherapy 89: 194-210. [CrossRef] [PubMed]

Hipp, Tracy N., Alexandra L. Bellis, Bradley L. Goodnight, Carolyn L. Brennan, Kevin M. Swartout, and Sarah L. Cook. 2017. Justifying Sexual Assault: Anonymous Perpetrators Speak out Online. Psychology of Violence 7: 82-90. [CrossRef]

Jahn, Danielle R., and Sally Spencer-Thomas. 2014. Continuing Bonds through After-Death Spiritual Experiences in Individuals Bereaved by Suicide. Journal of Spirituality in Mental Health 16: 311-24. [CrossRef]

Janoff-Bulman, Ronnie. 2002. Shattered Assumptions: Towards a New Psychology of Trauma. New York: Free Press. Jordan, John, and John McIntosh. 2010. Grief after Suicide: Understanding the Consequences and Caring for the Survivors. New York: Taylor and Francis. 
Keen, Catherine, Murray Craig, and Sheila Payne. 2013. A Qualitative Exploration of Sensing the Presence of the Deceased Following Bereavement. Mortality 18: 339-57. [CrossRef]

Klass, Dennis, Silverman Phyllis, and Steven Nickman. 1996. Continuing Bonds: New Understandings of Grief. Philadelphia: Taylor \& Francis.

Krysinska, Karolina E. 2003. Loss by Suicide: A Risk Factor for Suicidal Behavior. Journal of Psychosocial Nursing and Mental Health Services 41: 34-41. [PubMed]

Krysinska, Karolina, Jahn Danielle R, Spencer-Thomas Sally, and Karl Andriessen. 2017. The Roles of Religion and Spirituality in Suicide Bereavement and Postvention. In Postvention in Action: The International Handbook of Suicide Bereavement Support. Edited by Karl Andriessen, Karolina Krysinska and Onja T. Grad. Boston: Hogrefe, pp. 186-96.

Kwilecki, Susan. 2009. Twenty-First Century American Ghosts: The After-Death Communication-Therapy and Revelation from Beyond the Grave. Religion and American Culture: A Journal of Interpretation 19: 101-33. [CrossRef]

Lester, David. 1982. Spiritualism and Suicide. OMEGA: Journal of Death and Dying 12: 45-49. [CrossRef]

Parker, Julie S. 2005. Extraordinary Experiences of the Bereaved and Adaptive Outcomes of Grief. OMEGA: Journal of Death and Dying 4: 257-83. [CrossRef]

Reed, Mark D. 1998. Predicting Grief Symptomatology among the Suddenly Bereaved. Suicide and Life-Threatening Behavior 28: 285-301. [CrossRef] [PubMed]

Rees, W. Dewi. 1971. The Hallucinations of Widowhood. British Medical Journal 4: 37-41. [CrossRef]

Root, Briana, and Julie Exline. 2014. The Role of Continuing Bonds in Coping with Grief: Overview and Future Directions. Death Studies 38: 1-8. [CrossRef] [PubMed]

Shafranske, Edward P., and Richard L. Gorsuch. 1984. Factors Associated with the Perception of Spirituality in Psychotherapy. Journal of Transpersonal Psychology 16: 231-41.

Shneidman, Edwin S. 1973. On the Nature of Suicide. San Francisco: Jossey-Bass.

Sormanti, Mary, and Judith August. 1997. Parental Bereavement: Spiritual Connections with Deceased Children. American Journal of Orthopsychiatry 6: 460-69. [CrossRef]

Spencer-Thomas, Sally. 2013. The Paradox of Traumatic Grief. Available online: http://sallyspencerthomas. blogspot.com/2013/09/the-paradox-of-traumatic-grief.html (accessed on 28 May 2018).

Steffen, Edith. 2014. Post-Traumatic Growth and Meaning Construction Following Sense of Presence Experiences in Bereavement: What Counseling Psychologists Can Do to Facilitate the Process? Paper presented at the APA Division 17 Counseling Psychology Conference, Washington, DC, USA, August 8-10.

Steffen, Edith M., and Adrian Coyle. 2010. Can 'Sense of Presence' experiences in bereavement be conceptualized as spiritual phenomena? Mental Health, Religion and Culture 13: 273-91. [CrossRef]

Steffen, Edith, and Adrian Coyle. 2011. Sense of Presence Experiences and Meaning-Making in Bereavement: A Qualitative Analysis. Death Studies 7: 579-609. [CrossRef]

Steffen, Edith, and Adrian Coyle. 2012. 'Sense of Presence' Experiences in Bereavement and their Relationship to Mental Health: A Critical Examination of a Continuing Controversy. In Mental Health and Anomalous Experience. Edited by Craig Murray. Hauppauge: Nova Science Publishers, pp. 33-56.

ter Kuile, Hagar, and Thomas Ehring. 2014. Predictors of Changes in Religiosity after Trauma: Trauma, Religiosity, and Posttraumatic Stress Disorder. Psychological Trauma: Theory, Research, Practice, and Policy 6: 353-60. [CrossRef]

Wiener, Lori, Alberta Aikin, Martha Blecher Gibbons, and Steven Hirschfeld. 1996. Visions of those who left too soon. American Journal of Nursing 96: 57-61. [CrossRef] [PubMed]

Wood, Lindsey, Byram Victoria, Gosling A. Sophie, and Julie Stokes. 2012. Continuing Bonds after Suicide Bereavement in Childhood. Death Studies 36: 873-98. [CrossRef] [PubMed]

World Health Organization. 2017. “Suicide." World Health Organization Media Centre. Available online: http:/ / www.who.int/mediacentre/factsheets/fs398/en/ (accessed on 19 December 2017).

Wortmann, Jennifer H., and Crystal L. Park. 2008. Religion and Spirituality in Adjustment Following Bereavement: An Integrative Review. Death Studies 32: 703-36. [CrossRef] [PubMed]

Wortmann, Jennifer H., Crystal L. Park, and Donald Edmonson. 2011. Trauma and PTSD Symptoms: Does Spiritual Struggle Mediate the Link? Psychological Trauma 3: 442-52. [CrossRef] [PubMed] 
Wright, Sylvia. 2006. Literature Review and Philosophical Discussion: Clues to the Afterlife from After-Death Communication. Journal of Spirituality and Paranormal Studies 29: 149-59.

Wuthnow, Robert. 2001. Spirituality and Spiritual Practice. In Sociology of Religion. Edited by Richard Fenn. Oxford: Blackwell Publishing, pp. 306-20.

Young, Ilanit Tal, Iglewicz Alana, Glorioso Danielle, Lanouette Nicole, Seay Kathryn, Ilapakurti Manjusha, and Sidney Zisook. 2012. Suicide Bereavement and Complicated Grief. Dialogues in Clinical Neuroscience 14: 177-86.

Zinnbaur, Brian, Pargament Kenneth, and Allie Scott. 1999. The Emerging Meanings of Religiousness and Spirituality: Problems and Prospects. Journal of Personality 67: 889-919. [CrossRef]

2018 by the authors. Licensee MDPI, Basel, Switzerland. This article is an open access article distributed under the terms and conditions of the Creative Commons Attribution (CC BY) license (http://creativecommons.org/licenses/by/4.0/). 